\title{
Endovascular Treatment of Pulmonary Artery Pseudoaneurysms Post-COVID-19 Pneumonitis
}

\author{
Nischal G. Kundaragi ${ }^{1}$ Sunil Kumar K. ${ }^{2} \quad$ Rahul Talwade $^{3} \quad$ Srivatsa Lokeshwaran $^{2}$ Priyanka V. K. ${ }^{3}$ \\ ${ }^{1}$ Department of Interventional Radiology and Interventional \\ Oncology (IRIO), Aster CMI Hospital, Bengaluru, Karnataka, India \\ 2 Department of Pulmonary Medicine, Aster CMI Hospital, Bengaluru, \\ Karnataka, India \\ Address for correspondence Nischal. G. Kundaragi, MD, DNB, FRCR, \\ Department of Interventional Radiology and Interventional Oncology \\ (IRIO), Aster CMI Hospital, Bengaluru, Karnataka 560092, India \\ (e-mail: drngkradiology@gmail.com).
}

${ }^{3}$ Department of Radiology, Aster CMI Hospital, Bengaluru, Karnataka, India

J Clin Interv Radiol ISVIR 2023;7:46-50.
Abstract
Keywords
- COVID-19 infection
- pulmonary artery pseudoaneurysm
- embolization
- hemoptysis

Pulmonary artery pseudoaneurysms (PAPs) are uncommon entities consisting of contained rupture of the pulmonary artery and are a potentially fatal cause of hemoptysis. We describe two index cases of left lower lobe PAPs and arterial ectasia post-COVID-19 pneumonitis and their endovascular treatment with Amplatzer vascular plug, coils, and glue.

\section{Introduction}

Pulmonary artery pseudoaneurysms (PAPs) are rare and potentially life-threatening if left untreated. They may occur in association with congenital cardiovascular anomalies, infection, trauma, neoplasm, vasculitis, or pulmonary hypertension. ${ }^{1-5}$ PAPs have classically been described to be associated with cavitary lesions of tuberculosis and termed Rasmussen's aneurysm. ${ }^{5}$ In the current literature, only two cases of PAPs associated with postviral infections have been reported. We report two cases of post-COVID-19 pneumonitis developing PAPs with arterial ectasia, diagnosed early and treated successfully with embolization.

\section{Case Report}

Case 1: A 70-year-old male patient presented to the emergency department with sudden onset of massive hemoptysis and breathlessness. He was a treated case of COVID-19 pneumonitis 1 month back and a known case of type 2 diabetes mellitus on insulin. Patient was intubated. Chest radiograph revealed consolidation of left lower lobe and discrete ground-glass opacities in right lower lobe. Immediate bronchoscopy revealed fresh blood coming from the left lower lobe bronchus. Attempts made to control bleeding by balloon tamponade were unsuccessful. Two units of packed red blood cells were transfused as hemoglobin dropped to $7.7 \mathrm{~g} / \mathrm{dL}$. High-resolution computed tomography (CT) chest done during COVID-19 infection revealed multifocal subpleural ground-glass opacities in both lower lobes. One month later CT scan showed formation of two thick-walled cavities in both the lower lobes with persistent adjacent ground-glass opacities. Further, CT thoracic angiogram done after hemoptysis revealed consolidation of left lower lobe, a cavity filled with hemorrhagic fluid, an ectatic lower lobe segmental pulmonary artery ( $40 \mathrm{~mm}$ length), and proximal pseudoaneurysm $(8.6 \times 6.2 \mathrm{~mm})$ on the medial aspect of cavity ( - Fig. 1A-F). The patient was taken for pulmonary article published online February 14, 2022
DOI https://doi.org/ 10.1055/s-0041-1740571. ISSN 2457-0214.
(C) 2022. Indian Society of Vascular and Interventional Radiology. All rights reserved.

This is an open access article published by Thieme under the terms of the Creative Commons Attribution-NonDerivative-NonCommercial-License, permitting copying and reproduction so long as the original work is given appropriate credit. Contents may not be used for commercial purposes, or adapted, remixed, transformed or built upon. (https://creativecommons.org/ licenses/by-nc-nd/4.0/)

Thieme Medical and Scientific Publishers Pvt. Ltd., A-12, 2nd Floor, Sector 2, Noida-201301 UP, India 


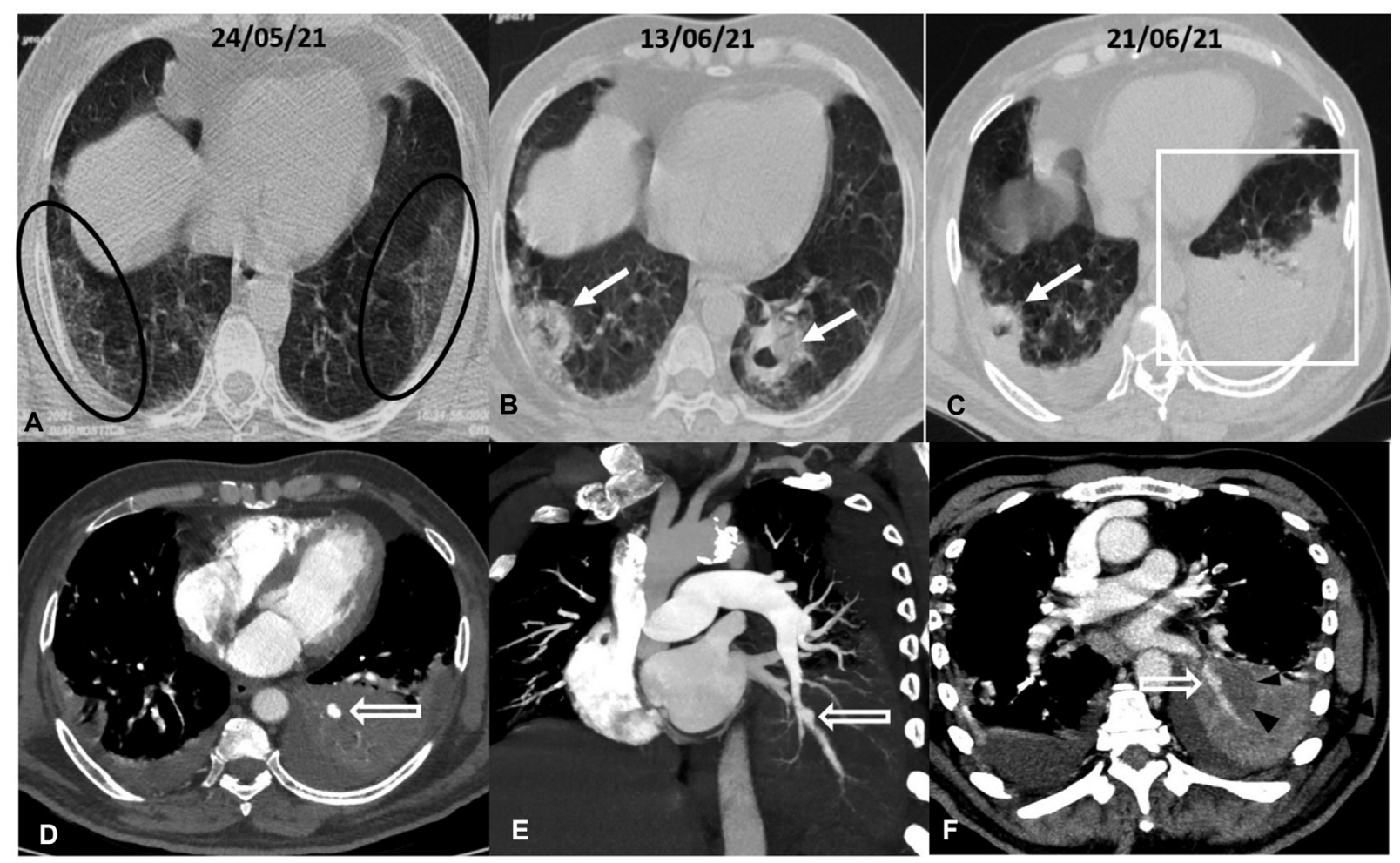

Fig. 1 (A-F) A 70-year-old man with COVID-19 pneumonitis with hemoptysis. (A) Computed tomography (CT) thorax axial images showing multifocal subpleural ground-glass opacities (large oval black rings). (B) CT thorax axial images done after 20 days showing persistent subpleural ground-glass opacities in bilateral lower lobes and formation of two thick-walled cavities in both lower lobes (white arrows). (C) Postmassive hemoptysis, nonenhanced CT (NECT) thorax axial images showing consolidation of left lower lobe (white square box) and subpleural thick-walled cavity seen in right lower lobe (white arrow). (D-F) Contrast-enhanced CT (CECT) thorax axial and oblique coronal images showing ectasia of segmental lower lobe pulmonary artery with proximal pseudoaneurysm (white open arrow). Nonenhancing hypodense cavity also seen lateral to ectatic pulmonary artery (black arrow heads) and mild pleural effusion.

artery embolization. Catheter-guided pulmonary angiogram and embolization was performed using a coaxially introduced 2.7F microcatheter (Progreat 2.0; Terumo), $5 \mathrm{~F}$ vertebral catheter (Cordis) on the support of $8 \mathrm{~F}$, and $63 \mathrm{~cm}$ Mullins sheath (Cook Medical, Bloomington, Indiana, United States). Angiograms were performed with hand injection. A total of $80 \mathrm{~mL}$ of nonionic contrast was used during the procedure. Superselective embolization of entire ectatic artery and pseudoaneurysm was performed using 0.18 " Micro-Nester coils $(6 \times 14 \mathrm{~mm}, 8 \times 14 \mathrm{~mm}$, and $5 \times 14 \mathrm{~mm}$; Cook Medical Inc.). Later, $8 \times 13.5 \mathrm{~mm}$ Amplatzer Vascular Plug Type IV (Abbott, Plymouth, Minnesota, United States) was deployed in the vertical segment of the artery through $5 \mathrm{~F}$ vertebral catheter. Arterial abnormality was found to be completely excluded from circulation after embolization ( - Fig. 2A-C).

Postembolization, the patient had chest pain, cough, and blood-tinged sputum for 2 days. Echocardiogram and cardiac ischemic marker (troponin I) were normal. No further hemoptysis was observed during his stay in the hospital. Bronchoalveolar lavage was negative for Koch's disease or other bacterial or fungal infection. Patient was discharged on the 6 th day postembolization and doing fine on follow-up of 65 days.

Case 2: A 57-year-old male patient presented to the emergency department with multiple episodes of hemoptysis since 7days. He was also a treated case of COVID-19 pneumonitis 1 month back and type 2 diabetes mellitus. In view of having similar presentation as previous patient, pulmonology department reviewed previous CT scan and referred the patient for $\mathrm{CT}$ thoracic angiogram. $\mathrm{CT}$ angiogram revealed thick-walled cavity in left lower lobe with subpleural patchy ground-glass opacities in bilateral lower lobes. Two pseudoaneurysms were seen in left lower lobe subsegmental pulmonary arteries, one near the medial wall and another near the anterior wall of the cavity ( - Fig. 3A-E). The patient was taken for pulmonary artery embolization. Pulmonary angiogram and embolization was performed using similar technique, catheters, and sheaths. Superselective embolization of both pseudoaneurysms were performed initially using glue (N-butyl-2-cyanoacrylate) and then by microcoils. Glue was prepared by using a 1:4 mixture of Histoacryl glue (B. Braun Melsungen AG) and Lipiodol (Guerbet). Glue mixture of 0.5 and $0.3 \mathrm{~mL}$ was used for medial and lateral pseudoaneurysms, respectively. Subsequent completion of embolization was performed using two each 0.18 " MicroNester coils $(5 \times 70 \mathrm{~mm}$ and $3 \times 30 \mathrm{~mm}$ in medial and $5 \times 70 \mathrm{~mm}$ in lateral pseudoaneurysm; Cook Medical Inc.) in proximal segments of arteries ( - Fig. 4A-D). Mild chest pain was observed following embolization for a day. Bronchoalveolar lavage was negative for Koch's disease or other bacterial or fungal infection. The patient was discharged on the 6th day postembolization, and doing fine on follow-up of 55 days. 


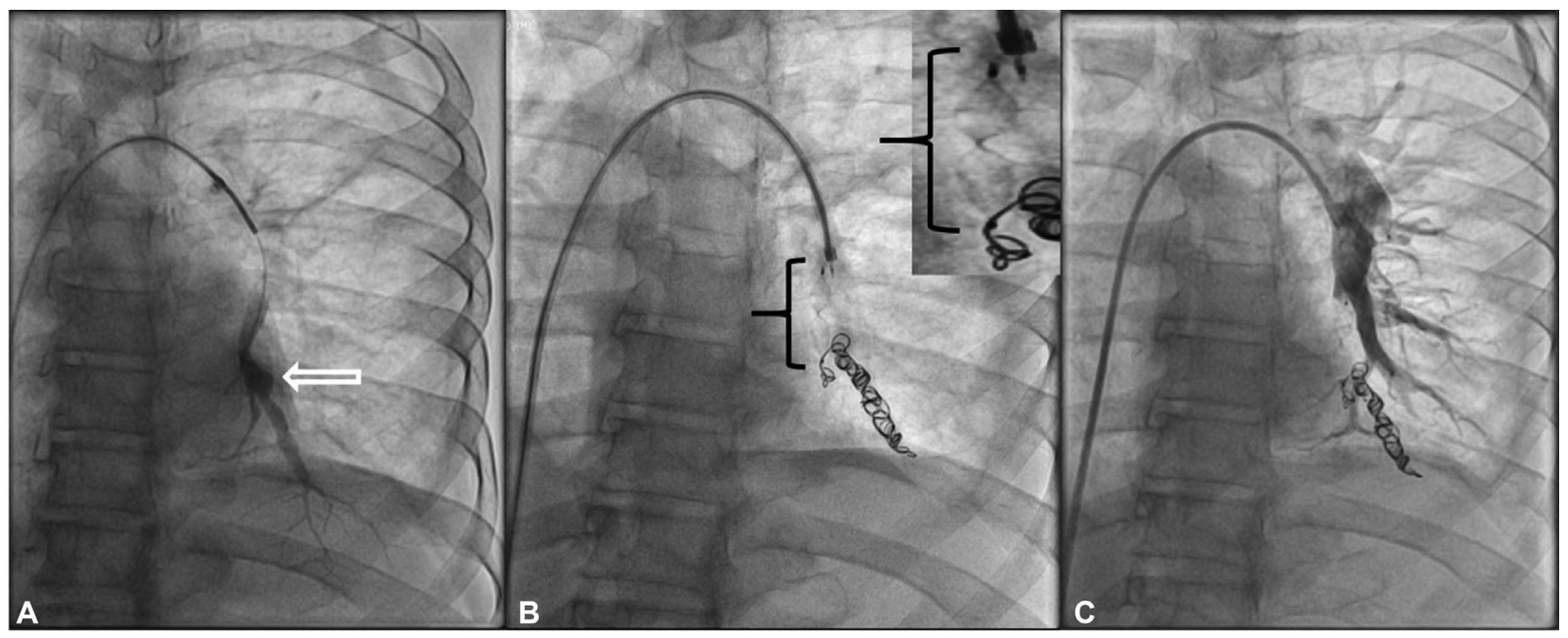

Fig. 2 (A-C) A 70-year-old man, post COVID 19 pneumonitis with haemoptysis. (A) Superselective Digital angiogram of left lower lobe subsegmental pulmonary artery, showing ectasia of segmental lower lobe pulmonary artery with proximal pseudoaneurysm (White open arrow). (B) Super selective coil and Amplatzer vascular plug Type 4 (Left curly bracket). Magnified image of vascular plug was shown in left upper quadrant. (C) Post-embolization pulmonary artery digital angiogram showing successful treatment.

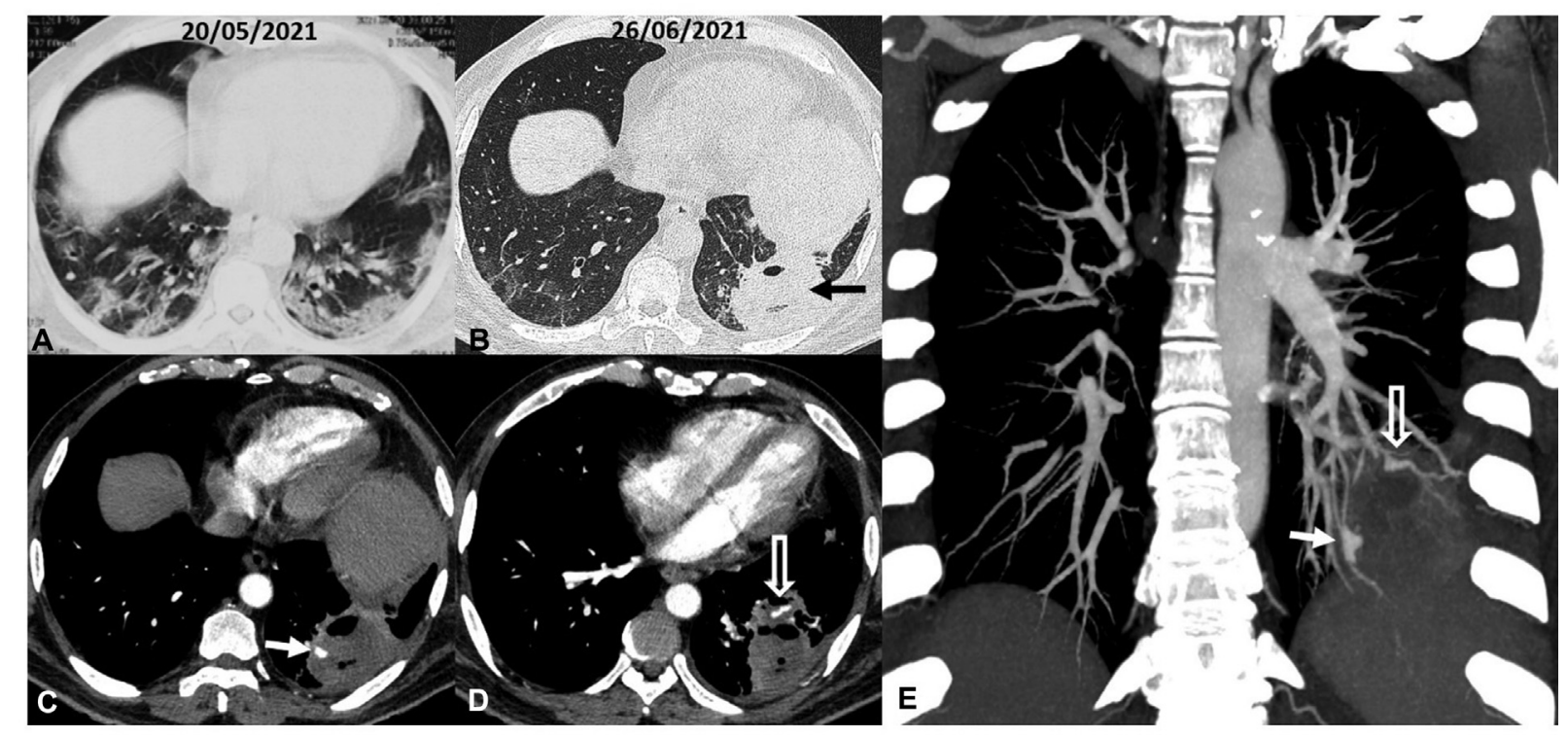

Fig. 3 (A-E) A 56-year-old man with COVID-19 pneumonitis and hemoptysis. (A) Computed tomography (CT) thorax axial image showing multifocal subpleural ground-glass opacities. (B) CT thorax done after 1 month after multiple episodes of hemoptysis showing persistent subpleural ground-glass opacities in bilateral lower lobes and thick-walled cavity left lower lobe (black arrow). (C, D) Posthemoptysis, contrastenhanced CT (CECT) thorax axial images showing cavity in left lower lobe with two pseudoaneurysms, one near the medial wall (white arrow) and another near the anterior wall of cavity (open arrow). (E) Maximum intensity projection (MIP) oblique coronal image showing pseudoaneurysms in subsegmental branches of left lower lobe pulmonary artery (arrows).

\section{Discussion}

PAPs are defined as focal dilatation of a segment of an artery involving only the external layers of the arterial wall (the media and adventitia) compared with a true aneurysm (involving all the layers), thus are associated with more risk of rupture leading to potentially fatal hemoptysis.

PAPs are classified as proximal or peripheral. Proximal PAPs involve the pulmonary trunk or interlobar artery and are often associated with pulmonary hypertension. Peripheral PAPs are seen in the intrapulmonary artery and are life- threatening if ruptured. The clinical presentation varies from compressive symptoms to fever to massive hemoptysis. ${ }^{1}$

Prevalence of PAPs range from 5 to $11 \%$ in patients presenting with hemoptysis or patients undergoing bronchial/pulmonary angiography. PAPs can be congenital or acquired. Common causes of acquired PAPs are trauma (often iatrogenic), infection, vasculitis (especially Behçet's disease), and neoplasm. Infection remains the leading cause of acquired PAPs. Infectious causes include tuberculosis, pyogenic bacteria, viral pneumonia, syphilis, or fungi. PAPs are commonly seen in tuberculosis compared with other 


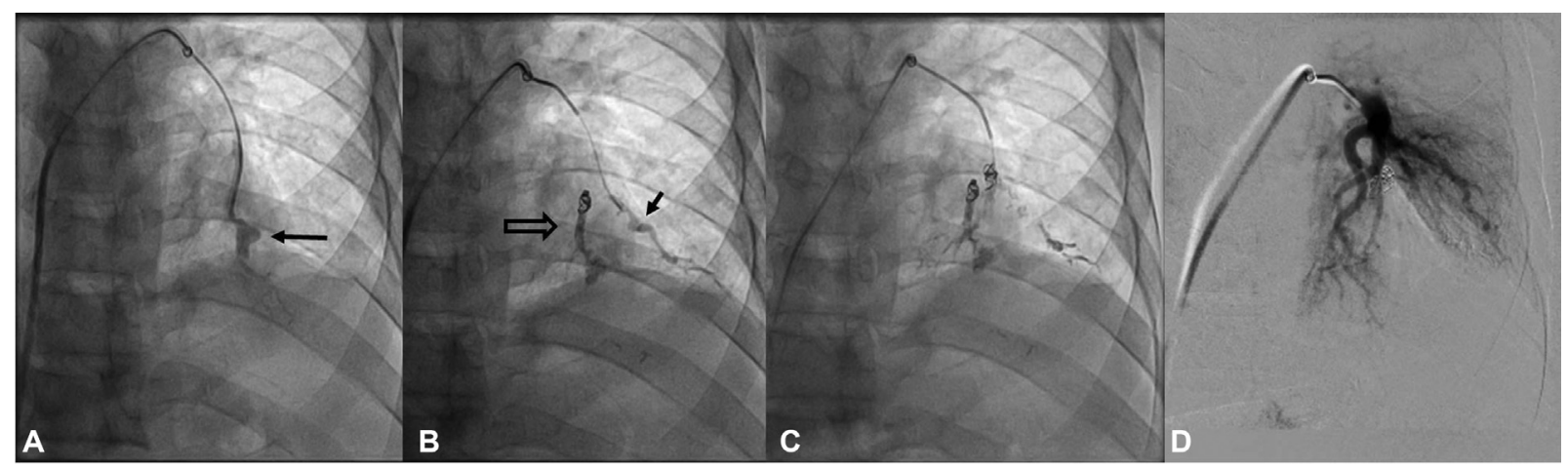

Fig. 4 (A-D) A 56-year-old man, post-COVID-19 pneumonitis with hemoptysis. (A) Superselective digital angiogram of left lower lobe subsegmental pulmonary artery, showing pseudoaneurysm (large black arrow). (B) Superselective digital angiogram of left lower lobe subsegmental pulmonary artery, showing pseudoaneurysm (small black arrow). Glue and coil embolization of medial pseudoaneurysm (black open arrow). (C, D) Postembolization digital angiogram showing successful treatment.

infections. Rasmussen's aneurysm is a PAP that results from tuberculosis, commonly seen in the upper lobe of the peripheral pulmonary artery. Pyogenic and mycotic PAPs can be seen in drug users, bacterial endocarditis, or septicaemia., ${ }^{1,3}$ Singular cases of PAPs associated with H1N1 viral pneumonia and post-COVID-19 viral pneumonia have been described in the left upper lobes. ${ }^{3,4}$ The development of PAP can be associated with severe inflammation and pulmonary vasculitis secondary to COVID-19 pnemonia. $^{3}$

Multidetector CT (MDCT) angiography has become the diagnostic method of choice for the evaluation of hemoptysis and PAPs. Because of their low prevalence, clinicians or interventional radiologists must review MDCTs with high suspicion for early detection and thereby providing lifesaving treatment. ${ }^{1-3}$

Khurram et $\mathrm{al}^{3}$ reported the first case of PAP in the left upper lobe post-COVID-19 pneumonitis. They illustrated left upper lobe PAP with an adjacent left apical pneumatocele which was treated by embolization using Amplatzer IV vascular plug (Abbot).

Lee et $\mathrm{al}^{4}$ described a left upper lobe PAP in a patient with H1N1 influenza viral pneumonia and methicillin-resistant Staphylococcus aureus, which was successfully treated with angioembolization by platinum coils. However, Smith et al ${ }^{5}$ reported a noninfectious case of PAPs in the right upper lobe associated with cavitating aspiration pneumonia. The authors treated their case by embolization using coils.

Endovascular embolization is the preferred method of managing PAPs. ${ }^{3,4}$ Different authors used different embolic agents ranging from coils, gel foam, vascular plugs to glue. ${ }^{6}$ Coil embolization of PAPs can offer selective embolization of the sac, however, can be associated with risk of rupture and distal migration of coils in case of wide neck aneurysms. Wide neck aneurysms and aneurysms arising from proximal/main pulmonary arteries can be treated by using bare metal stents (caging technique) or balloon-assisted coiling or stent-graft; however, these techniques will increase the cost of procedure and possible risk of graft infection in cases of infective etiology. ${ }^{7,8}$ In some cases, coil embolization of arterial branch supplying the aneurysmal sac may still allow perfusion because of bronchopulmonary shunts. Embolization PAPs with
Amplatzer vascular plug has some advantages like increased precision and control while deployment; however, plugs are difficult to use in case of peripheral pulmonary arteries because of large access profile and deploying devices. Glue (N-butyl-cyanoacrylate) and thrombin are used as liquid embolic agents to treat PAPs.

Glue is permanent and highly effective compared with thrombin. Unstable microcatheter position due to dynamically pulsating pulmonary artery circulation and Rasmussen's aneurysm with underlying fibrocavitory changes make glue embolization technically more feasible than coil embolization. ${ }^{7}$ However, risks of nontargeted embolization, pulmonary infarction, or catheter adhesion can occur with glue embolization, if not performed superselectively or by inexperienced operator. PAPs can also be treated by percutaneous CT-guided or ultrasound-guided injection of thrombin or cyanoacrylate glue in cases refractory to endovascular management. ${ }^{7,9} \mathrm{Em}$ bolization of PAPs when performed meticulously using desired embolic materials has a good technical and clinical success rate. In case 1 , we used coils and Amplatzer IV vascular plug. In case 2, we used glue due to high risk of rupture in view of postCOVID vasculitis. In case 2 , selective positioning of the vascular plug was not possible because of a short vascular stump of the segmental pulmonary artery from its origin and bifurcation. Selective deployment and repositioning are the advantages of Amplatzer vascular plugs and has been successfully used in pulmonary arteriovenous malformations. ${ }^{10}$ Advantages and disadvantages of different treatment options are mentioned in - Table 1.

In conclusion, two cases presented here and a single case reported by Khurram et al ${ }^{4}$ have similar features like known type 2 diabetes mellitus on treatment, developed PAPs in left lung lobes after 1 to 2 months of COVID-19 pneumonitis, and in all cases PAPs were associated with lung cavities. Thus, both the index cases presented here provide valuable information about post-COVID 19 arterial ectasia/PAP formation, clinical and imaging presentations, and their successful treatment by embolization.

Conflict of Interest

None declared. 
Table 1 Treatment of pulmonary artery pseudoaneurysms (PAPs)

\begin{tabular}{|c|c|c|c|c|}
\hline $\begin{array}{l}\text { Segment in- } \\
\text { volved }\end{array}$ & Incidence & Treatment & Advantages & Disadvantages/Complications \\
\hline Main PAPs & Uncommon & $\begin{array}{l}\text { Stenting } \pm \\
\text { Embolization }\end{array}$ & $\begin{array}{l}\text { - Stents are helpful in wide } \\
\text { neck PAPs } \\
\text { - Main PA aneurysms }\end{array}$ & $\begin{array}{l}\text { - Possible graft infection } \\
\text { - Endoleak } \\
\text { - Embolization-associated compli- } \\
\text { cations } \\
\text { - Expensive }\end{array}$ \\
\hline \multirow{5}{*}{$\begin{array}{l}\text { Segmental and } \\
\text { subsegmental } \\
\text { PAPs }\end{array}$} & \multirow[t]{5}{*}{ Common } & Embolization using & & \\
\hline & & Coils & Superselective embolization & $\begin{array}{l}\text { - Risk of rupture } \\
\text { - Risk of migration }\end{array}$ \\
\hline & & Glue & $\begin{array}{l}\text { - Liquid embolic material } \\
\text { - Permanent } \\
\text { - Inexpensive }\end{array}$ & $\begin{array}{l}\text { - Nontargeted embolization } \\
\text { - Pulmonary infarction } \\
\text { - Catheter adhesion } \\
\text { - Need more expertise }\end{array}$ \\
\hline & & Vascular plugs & $\begin{array}{l}\text { - Increased precision and } \\
\text { controlled deployment } \\
\text { - Retrieve and reposition }\end{array}$ & $\begin{array}{l}\text { - Need large access profile and large } \\
\text { vessel diameter } \\
\text { - Expensive }\end{array}$ \\
\hline & & $\begin{array}{l}\text { Thrombin (- } \\
\text { intravascular/ } \\
\text { percutaneous) }\end{array}$ & $\begin{array}{l}\text { - Liquid embolic material } \\
\text { - Feeding vessel could not be } \\
\text { identified with pulmonary } \\
\text { angiography } \\
\text { - Percutaneous injection after } \\
\text { inadequate treatment by } \\
\text { coil embolization }\end{array}$ & $\begin{array}{l}\text { - Less effective in wide neck aneur- } \\
\text { ysms and proximal high flow PAPs }\end{array}$ \\
\hline
\end{tabular}

\section{References}

1 Guillaume B, Vendrell A, Stefanovic X, Thony F, Ferretti GR. Acquired pulmonary artery pseudoaneurysms: a pictorial review. Br J Radiol 2017;90(1073):20160783

2 Chen Y, Gilman MD, Humphrey KL, et al. Pulmonary artery pseudoaneurysms: clinical features and CT findings. AJR Am J Roentgenol 2017;208(01):84-91

3 Khurram R, Karia P, Naidu V, Quddus A, Woo WL, Davies N. Pulmonary artery pseudoaneurysm secondary to COVID-19 treated with endovascular embolisation. Eur J Radiol Open 2021;8:100346

4 Lee JC, Walters DL, Slaughter RE. Angioembolisation of pulmonary artery pseudoaneurysm arising in H1N1 influenza viral pneumonia. Heart Lung Circ 2011;20(09):599-601

5 Smith CB, Patel BN, Smith JP. Pulmonary artery pseudoaneurysm arising secondary to cavitary pneumonia. Radiol Case Rep 2015;7 (03):654
6 Park HS, Chamarthy MR, Lamus D, Saboo SS, Sutphin PD, Kalva SP. Pulmonary artery aneurysms: diagnosis \& endovascular therapy. Cardiovasc Diagn Ther 2018;8(03):350-361

7 Giragani S, Balani A, Mallu GR, et al. Endovascular glue embolization for control of massive hemoptysis caused by peripheral pulmonary artery pseudoaneurysms: report of 7 cases. Lung India 2019;36(01):8-13

8 Koneru $\mathrm{H}$, Biswas Roy S, Islam M, et al. Pulmonary artery pseudoaneurysm: a rare cause of fatal massive hemoptysis. Case Rep Pulmonol 2018;2018:8251967

9 Shin S, Shin TB, Choi H, et al. Peripheral pulmonary arterial pseudoaneurysms: therapeutic implications of endovascular treatment and angiographic classifications. Radiology 2010;256(02): 656-664

10 Lee SY, Lee J, Kim YH, et al. Efficacy and safety of AMPLATZER vascular plug type IV for embolization of pulmonary arteriovenous malformations. J Vasc Interv Radiol 2019;30(07):1082-1088 